\title{
Therapeutic targets against gastric cancer stem cells interacting with tumor microenvironment
}

\author{
Tomoyuki Uchihara, Takatsugu Ishimoto, Atsuko Yonemura, Hideo Baba \\ Department of Gastroenterological Surgery, Graduate School of Medical Science, Kumamoto University, Kumamoto 860-8556, \\ Japan.
}

Correspondence to: Prof. Hideo Baba, Department of Gastroenterological Surgery, Graduate School of Medical Science, Kumamoto University, Kumamoto 860-8556, Japan. E-mail: hdobaba@kumamoto-u.ac.jp How to cite this article: Uchihara T, Ishimoto T, Yonemura A, Baba H. Therapeutic targets against gastric cancer stem cells interacting
with tumor microenvironment. J Cancer Metastasis Treat 2018;4:9. http://dx.doi.org/10.20517/2394-4722.2017.81

Received: 21 Nov 2017 First Decision: 5 Jan 2018 Revised: 22 Jan 2018 Accepted: 22 Jan 2018 Published: 26 Feb 2018

Science Editor: Masayuki Watanabe Copy Editor: Jun-Yao Li Production Editor: Huan-Liang Wu

\begin{abstract}
Gastric cancer (GC) is a major cause of cancer-related deaths worldwide. The existence of cancer stem cells (CSCs) is known to be the main reason for resistance to anticancer agents as well as for the development of distant metastases. Although CSCs themselves harbor self-renewal and differentiation abilities, the tumor microenvironment that surrounds CSCs provides secreted factors and supports angiogenesis and is thus responsible for the maintenance of their CSC properties. The current review provides information regarding the impact of the tumor microenvironment on gastric CSCs, which will support the development of novel therapeutic strategies for targeting gastric CSCs.
\end{abstract}

Keywords: Gastric cancer stem cells, stem cell markers, tumor microenvironment, gastric cancer treatment

\section{INTRODUCTION}

Although the proportion of individuals with gastric cancer (GC) has declined for decades, GC continues to be a major cause of cancer-related deaths worldwide ${ }^{[1-3]}$. Despite improvements in the treatment of GC, the clinical outcome of patients with advanced GC after curative resection is still poor, which is mainly due to recurrence and metastasis ${ }^{[4]}$. Therefore, new treatment options for this disease must be developed.

Recent evidence has increasingly indicated that the heterogeneity of the tumor is a consequence of cancer stem cells (CSCs), which are deeply involved in tumor progression and metastasis ${ }^{[5-7]}$. Malignant tumors have been reported to exhibit obvious histologic heterogeneity. In 1937, Furth et al. ${ }^{[8]}$ demonstrated that a single leukemia cell could cause systemic disease in recipient mice. However, it took a long time for the concept of

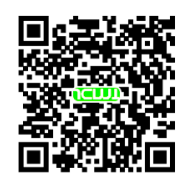


CSCs to be widely recognized. CSCs of acute myelogenous leukemia (AML) were first identified by Bonnet and Dick ${ }^{[9]}$ in 1997, and they also determined that the CD34+ CD38- fraction of AML tumor cells enhances tumorigenicity after continuous transplant into immunodeficient mice. CSCs have subsequently been found in various types of solid tumors ${ }^{[10-12]}$. Gastric CSCs (GCSCs) have been vigorously investigated in studies using GC cell lines and primary GC tissues ${ }^{[13-15]}$.

The current review provides recent evidence for the regulation of GCSCs in the tumor microenvironment and for GCSC-targeted treatments.

\section{MARKERS OF GCSCS}

\section{CD44}

CD44 was first identified as a potential GCSC marker in a study using GC cell lines. The CD44-positive fraction in these GC cell lines showed the ability to form spheroids in vitro and demonstrated tumorigenicity in vivo when injected into the stomach wall or when injected subcutaneously into immunodeficient mice ${ }^{[16]}$. Furthermore, a combination of the cell surface markers CD44 and CD24 has been examined in GC cell lines and primary GC tissues from five patients using fluorescence-activated cell sorting. The authors of that study found that the CD44+/CD24+ fraction demonstrated a higher tumorigenicity compared with the CD44-/ CD24- fraction when injected into immunodeficient mice. Therefore, not only do these cells have the ability to self-replicate and produce differentiated offspring, the combined expression of CD44+/CD24+ acts as a putative GCSC marker ${ }^{[17]}$. CSCs were isolated from the peripheral blood of GC patients using the cell surface markers CD44 and CD54, and tumors similar to the original human tumor were generated when the cells were injected into immunodeficient mice. The same cells differentiated into gastric epithelial cells in vitro and self-renewed in vivo and in vitro. These results suggest that the combination of CD44+/CD54+ can also be used as a potential cell surface marker for GCSC ${ }^{[18]}$. Epithelial cell adhesion molecule (EpCAM) and CD44 have also been identified as CSC markers in various types of tumors. The EpCAM+/CD44+ fraction from human GC tissues grew into tumors in immunodeficient mice, maintained a differentiated phenotype and reproduced the morphological and phenotypical heterogeneities of the original gastric tumors. These cells acquired greater tolerance to anticancer agents than other subtypes of cells ${ }^{[19]}$.

\section{Lgr5}

Lgr5 has received substantial attention as a new GCSC marker. Initially, Lgr5 was identified in stem cells within hair follicles, the small intestine, large intestine and stomach ${ }^{[2,21]}$. Lgr5+ stem cells in the intestinal crypts are interspersed among terminally differentiated Paneth cells, which act as guardians of the stem cells by providing essential niche signals ${ }^{[2]}$, but the role of Lgr5+ cells in the stomach is not fully understood. In addition, Notch signaling regulates gastric antral Lgr5 stem cell function. An analysis of gastric organoids revealed that Notch signaling is intrinsic to the epithelium and that it regulates growth. Furthermore, in one study, in vivo Notch manipulation affected the efficiency of organoid initiation from glands and single Lgr5GFP stem cells, which indicates the regulation of stem cell function by Notch. Moreover, the authors of that study showed that, compared with control stem cells, stem cells in which Notch signaling was activated competed more effectively for niche spots, as they rapidly spread within the stem cell niche ${ }^{[23]}$. More recently, Lgr5-positive chief cells were defined as a major cell-of-origin of gastric cancer. That study revealed Lgr5 expression in a subpopulation of chief cells in mouse and human corpus glands. Using a non-variegated Lgr5-2A-CreERT2 mouse model, the authors demonstrated that the division of these Lgr5-positive cells depended on the occurrence of Wnt signaling at the time of injury. It has become clear that Lgr5-positive cells generate all the cells that form the stomach tissue and that they are able to repair wounds within the stomach. Additionally, it was also found that gastric cancer developed when cancer-associated genes were activated in Lgr5-positive stem cells. This suggests that tissue stem cells are necessary for the repair and regeneration of the injured stomach might change to $\mathrm{CSCs}^{[24]}$. As described above, LGR5 acts as a GCSC marker of gastric cancer progression. 


\section{CD133}

One study examined the expression of three putative CSC markers, including ATP-binding cassette subfamily B member 1, ATP-binding cassette sub-family G member 2, and CD 133, in 90 human GC tissue samples and three human GC cell lines. The authors concluded that the expression levels of these markers in GC varied with the degree of differentiation, while poorly differentiated GC expressed high levels of these markers. Furthermore, CD133 expression in GC cells could be divided into two forms: luminal expression in the gland and cytoplasmic expression. A multivariate analysis revealed that the expression of CD133 in the cytoplasm was an independent prognostic factor in $\mathrm{GC}^{[25,26]}$.

\section{Other GCSC markers}

In addition, aldehyde dehydrogenase 1 (ALDH1) has been identified as a marker of GCSCs. ALDH1+ cells derived from a diffuse-type GC cell line had a higher tumorigenic capacity in vitro and in vivo compared with ALDH1- cells and were capable of self-renewal and the generation of heterogeneous cell populations. Moreover, regenerating islet-derived family member 4 (REG4) was overexpressed in ALDH1+ GCSCs, and ALDH1 and REG4 expression were down-regulated by transforming growth factor- $\beta$ (TGF- $\beta$ ), which correlated with a reduction in the GCSC population and tumorigenicity ${ }^{[27,28]}$. CD90+ cells, which possessed a greater ability to initiate tumors in vivo compared with CD90- cells, could re-establish the cellular hierarchy of tumors from single-cell implantation, which demonstrates their self-renewal properties. In addition, previous studies on chemo-resistance revealed that ERBB2 was overexpressed in approximately $20 \%$ $25 \%$ of the gastric primary tumor models, which correlated with the higher level of CD90 expression in these tumors ${ }^{[29,30]}$. Moreover, trastuzumab treatment could decrease the CD90+ population in these tumor masses and could suppress tumor growth when combined with traditional chemotherapy. Taken together, this evidence suggests that CD90 may be another potential candidate marker of GCSCs ${ }^{[30]}$. The CD71fraction of GC cells was enriched after treatment with 5 -fluorouracil and accumulated during the Go/G1 cell cycle phase. This cell subtype also exhibited high drug resistance to conventional chemotherapy, which demonstrates its stem cell-like properties. Limiting dilution and serial transplantation assays revealed that the CD71- cell fraction had higher tumorigenicity than the CD71+ cell fraction ${ }^{[31]}$.

More recently, new tissue stem cell markers have been proposed. Lrig1, which is a marker of proliferative and quiescent stem cells in the skin and intestine, is a marker of gastric corpus epithelial progenitor cells that are capable of repopulating the damaged oxyntic mucosa via differentiation into normal gastric lineage cells in the mouse stomach. Lineage labelling using Lrig1-CreERT2/+; R26R-YFP/+ (Lrig1/YFP) or R26R-LacZ/+ (Lrig1/LacZ) mice demonstrated that the Lrig1-YFP-marked cells were gastric progenitor cells ${ }^{[32]}$. Likewise, Mist1 is a marker of quiescent stem cells in the gastric corpus isthmus. Mist1-positive stem cells serve as a cell-of-origin for intestinal-type GCs, and have the combination of Kras and Apc mutations; Mist1-positive cells are also the cell-of-origin of diffuse-type GCs when E-cadherin expression is lost ${ }^{[33]}$. Potential GCSC markers are summarized in Table 1.

\section{GCSC REGULATION IN THE TUMOR MICROENVIRONMENT}

The tumor microenvironment consists of various types of cells including immune cells, endothelial cells, and fibroblasts, in addition to the extracellular matrix, and has a large impact on tumor progression ${ }^{[34,35]}$. Cancer cells remodel their microenvironment through the secretion of growth factors and proteases, while stromal cells also affect cancer cells through the secretion of soluble factors such as matrix metalloproteinases, TGF- $\bigotimes_{1}$, Wnt ligands, bone morphogenetic proteins, stromal cell-derived factor 1 and exosomes ${ }^{[36-38]}$. Tissue stem cells are located beside the surrounding environment termed a "stem cell niche" where they play critical roles in tissue homeostasis by maintaining their ability to self-renew and differentiate ${ }^{[39,40]}$.

In the tumor microenvironment, myofibroblasts, which are also known as cancer-associated fibroblasts (CAFs), share characteristics with smooth muscle cells and fibroblasts. CAFs enhance tumor progression through the secretion of soluble factors such as growth factors and cytokines in various tumor types ${ }^{[41-43]}$. 
Table 1. Gastric cancer stem cell markers

\begin{tabular}{|c|c|c|c|c|}
\hline Marker & General function & Significance & Therapeutic targets & References \\
\hline CD44 & $\begin{array}{l}\text { Cell adhesion molecule, hyaluronic acid } \\
\text { receptor }\end{array}$ & $\begin{array}{l}\text { Tumorigenicity, spheroid } \\
\text { formation, chemoresistance }\end{array}$ & $\begin{array}{l}\text { Glutathione metabolism } \\
\text { (CD44v) }\end{array}$ & {$[16,28,58]$} \\
\hline CD24/CD44 & Cell adhesion molecule & Tumorigenicity & & [17] \\
\hline CD54/CD44 & Cell adhesion molecule & $\begin{array}{l}\text { Tumorigenicity, hierarchical } \\
\text { organization }\end{array}$ & & {$[18]$} \\
\hline Lgr5 & $\begin{array}{l}\text { Wnt target gene, restriction to the crypt } \\
\text { base }\end{array}$ & Tumorigenicity & $\begin{array}{l}\text { Notch-mTOR signal } \\
\text { miR-132 }\end{array}$ & {$[21,23,24,46,59-62]$} \\
\hline Lrig1 & Regulatory factor of cell cycle & Tumorigenicity & Not shown & [32] \\
\hline Mist1 & Transcriptional regulator & Tumorigenicity & Not shown & [33] \\
\hline EpCAM/CD44 & Cell adhesion molecule & $\begin{array}{l}\text { Tumorigenicity, phenotypical } \\
\text { heterogeneity, chemoresistance }\end{array}$ & Not shown & {$[19]$} \\
\hline ALDH1 & Detoxifying enzyme & $\begin{array}{l}\text { Tumorigenicity, phenotypical } \\
\text { heterogeneity }\end{array}$ & Not shown & {$[27,28]$} \\
\hline CD90 & Immunoglobulin superfamily & $\begin{array}{l}\text { Tumorigenicity, trastuzumab } \\
\text { reduce the } C D 90^{+} \text {population }\end{array}$ & CD90 & {$[29,30]$} \\
\hline CD71 & Transferrin receptor & $\begin{array}{l}\text { Tumorigenicity, } \\
\text { chemoresistance, tumor cell } \\
\text { invasion }\end{array}$ & Not shown & {$[31]$} \\
\hline CD133 & Pentaspan transmembrane glycoprotein & $\begin{array}{l}\text { Poorly differentiated gastric } \\
\text { cancer, independent prognostic } \\
\text { factor }\end{array}$ & CD133 & {$[25,26,56,63]$} \\
\hline
\end{tabular}

One study showed that CAFs significantly increased the number of spheroid colonies, the expression level of CSC markers and the fraction of side population cells in scirrhous GC cell lines. The influence of CAFs was significantly inhibited by TGF- $\beta$ inhibitors, but not by fibroblast growth factor receptor or cMet inhibitors. These findings suggest that CAFs might promote CSC properties in scirrhous GC through TGF- $\beta$ signaling ${ }^{[44]}$. IL-17B induced the expression of the self-renewal-related genes Nanog, Sox2, and Oct4 in mesenchymal stem cells and promoted tumor progression. After treatment with exogenous IL-17B, the supernatant from cultured mesenchymal stem cells promoted the proliferation and migration of GC cells. This suggests that IL-17B might promote the production of soluble factors by mesenchymal stem cells, which leads to GC progression $^{[45]}$.

A recent compelling study demonstrated that nerves help to regulate both normal and neoplastic stem cell dynamics in the gastrointestinal stem cell niche. The authors of that study utilized a series of Dclk1CreERT mouse models to show that acetylcholine from nerves and from Dclk1+ tuft cells, which acted as intermediary niche cells to coordinate neural input to help regulate subsequent stem cell activity, induced nerve growth factor in gastric epithelial cells; this in turn promoted neuron expansion and tumorigenesis ${ }^{[46]}$.

\section{CURRENT TREATMENT OF GC AND THE POTENTIAL FOR TARGETING GCSCS}

Surgical resection is currently the only curative modality to eliminate GC. Endoscopic screening has become widespread, however, GCs are frequently diagnosed at an advanced stage, when the clinical outcomeis still poor. Even after curative surgery, patients with advanced GC still experience recurrence, which implies that undetectable GC cells exist in the blood at the time of surgery. Based on this possibility, definitive evidence has been found that multimodal treatments consisting of surgery with neoadjuvant chemotherapy, adjuvant chemotherapy, or chemoradiation would improve the poor outcomes compared with surgery alone.

In recent years, several molecular-targeted agents have been investigated in various combinations with conventional treatment as a first-line chemotherapy against advanced GC. The Trastuzumab for Gastric Cancer (ToGA) trial revealed that trastuzumab, a recombinant monoclonal antibody against HER2 (also known as ERBB2), combined with fluoropyrimidine plus cisplatin provided a significant survival advantage compared with fluoropyrimidine plus cisplatin alone in patients with HER2-positive advanced GC ${ }^{[29,47,48]}$. The ramucirumab for patients with previously treated advanced gastric or gastro-esophageal junction 


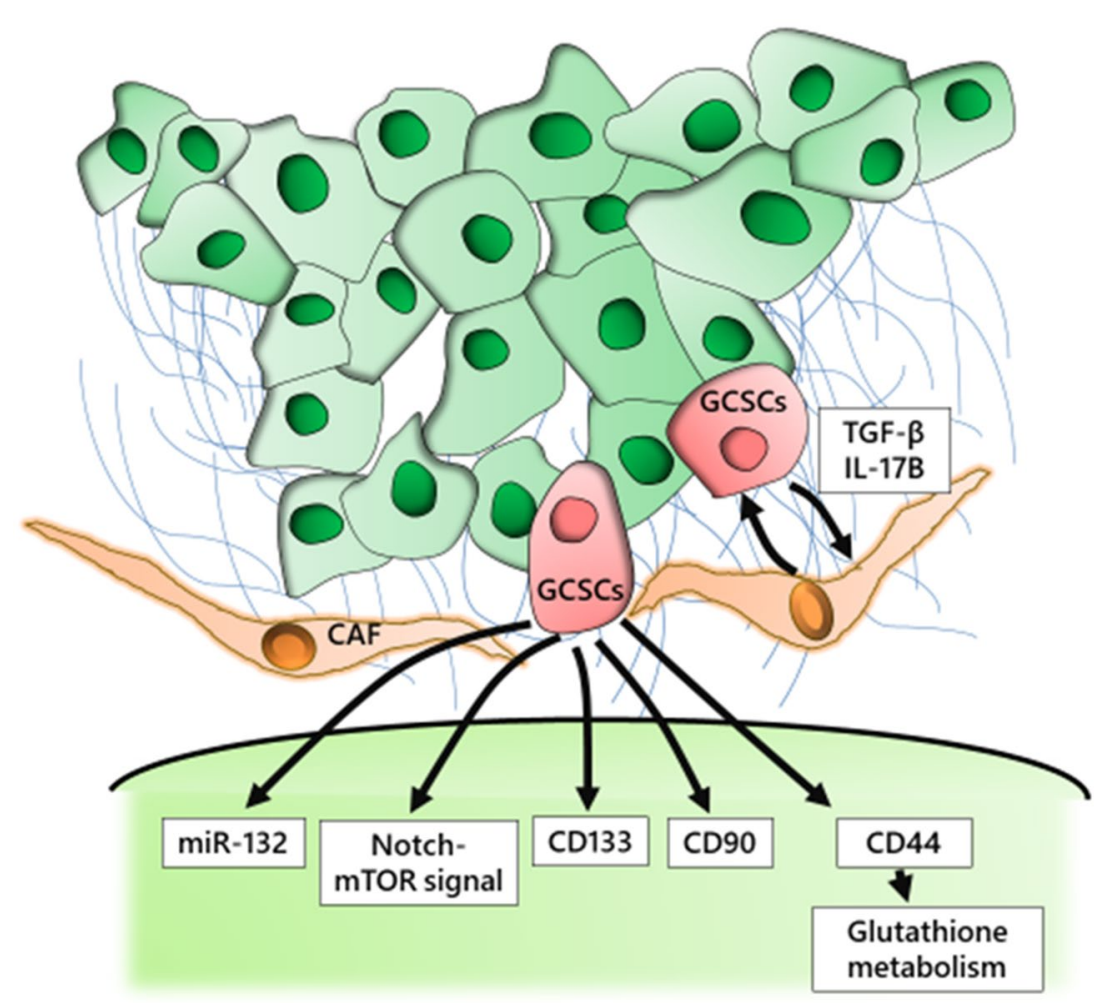

Figure 1. GCSCs in the microenvironment and the activated pathway in GCSCs. GCSCs: Gastric cancer stem cells; CAF: cancer-associated fibroblasts; TGF: transforming growth factor; IL: interleukin

adenocarcinoma (RAINBOW) trial showed that the combination of ramucirumab and paclitaxel significantly improved overall survival compared with placebo plus paclitaxel and that this combination could be regarded as a new standard second-line chemotherapy for patients with advanced $\mathrm{GC}^{[49,50]}$.

Immune checkpoint blockade is new topic in cancer therapy. The immune checkpoint pathways, which basically maintain self-tolerance and limit collateral tissue damage during anti-microbial immune responses, can be co-opted by cancer to evade immune destruction ${ }^{[51]}$. Nivolumab is a human monoclonal IgG4 antibody that blocks the human programmed cell death-1 (PD-1) receptor. Preliminary data from a double-blinded, randomized, phase III trial (ONO-4538/BMS-936558) demonstrated the efficacy of nivolumab as salvage treatment as a third- or later line of treatment in 493 patients with advanced gastric or gastroesophageal junction cancer compared with placebo (NCT02267343). Finally, a clinical study demonstrated that nivolumab was effective as the salvage treatment for pretreated advanced GC with significantly improved clinical outcomes compared with the placebo ${ }^{[52]}$.

To develop a treatment strategy to target GCSCs, we must select critical molecules that regulate the biological characteristics of CSCs [Figure 1]. Several molecules have been investigated as possible targets including those associated with specific signaling pathways, cell surface markers, and microenvironmental factors. We previously used K19-Wnt1/C2mE mice, a transgenic GC mouse model, to demonstrate that the CD44 variant isoform $(\mathrm{CD} 44 \mathrm{v})$, one of the cell surface markers of GCSCs, contributed to the defense against reactive oxygen species by stabilizing the glutamate-cystine transporter subunit $\mathrm{xCT}$ and promoting the synthesis of the primary intracellular antioxidant glutathion $e^{[53,54]}$. Moreover, we found that CD44v expression was upregulated in these gastric tumor cells. We also showed that the inhibition of the cystine transport system $\mathrm{xc}(-)$ with sulfasalazine, an inhibitor of xCT-dependent cystine transport, suppressed the progression of gastric tumors in these transgenic mice ${ }^{[55]}$. Our findings suggest that targeted therapy against the CD44V-xCT system may provide a strategy for the targeting of CD44v positive GCSCs. CD133 was a potential therapeutic 
target for antibody-drug conjugates (ADC), which was proven by binding mouse anti-human CD133 monoclonal antibody to highly cytotoxic monomethyl auristatin F, ultimately inducing apoptosis in cancer cells with high levels of $\mathrm{CD} 133$ expression ${ }^{[56]}$. However, a recent study demonstrated that the hierarchical organization that involves CSCs and non-CSCs may be reversible through epigenetic gene regulation, which suggests that therapeutic strategies that target GCSCs themselves might be insufficient to eliminate cancer cells ${ }^{[57]}$.

\section{CONCLUSION}

Molecular-targeted agents have been developed as a new treatment strategy and have been applied to various types of solid tumors. These developed agents have been assessed in diverse combinations with conventional chemotherapy as a treatment against advanced tumors including GC. However, the success of molecular-targeted agents for GC has been limited, and the prognosis of patients with advanced GC is still poor. Based on accumulating evidence, GCSCs are deeply involved in GC progression. Moreover, the tumor microenvironment that surrounds GCSCs forms the CSC niche and allows the stem cells to give rise to a hierarchy of proliferative and non-GCSC cells. Targeting the critical pathways and molecules between GCSCs and their environment may therefore represent a promising therapeutic strategy, and may provide a complementary approach to conventional therapies that target the malignant cells themselves. This review describes recent progress and evidence concerning the markers of GCSCs, related molecules within the GCSC niche and treatment targets. Further elucidation of the molecular mechanisms of GCSC regulation may lead to the development of novel treatment strategies that target GCSCs.

\section{DECLARATIONS}

\section{Authors' contributions}

Writing manuscript: Uchihara T, Ishimoto T, Yonemura A, Baba H

Organized data: Uchihara T, Ishimoto T

Financial support and sponsorship

None.

\section{Conflicts of interest}

There are no conflicts of interest.

\section{Patient consent}

Not applicable.

\section{Ethics approval}

Not applicable.

\section{Copyright}

(c) The Author(s) 2018.

\section{REFERENCES}

1. Bertuccio P, Chatenoud L, Levi F, Praud D, Ferlay J, Negri E, Malvezzi M, La Vecchia C. Recent patterns in gastric cancer: a global overview. Int J Cancer 2009;125:666-73.

2. Taghavi S, Jayarajan SN, Davey A, Willis AI. Prognostic significance of signet ring gastric cancer. J Clin Oncol 2012;30:3493-8.

3. Jemal A, Bray F, Center MM, Ferlay J, Ward E, Forman D. Global cancer statistics. CA Cancer J Clin 2011;61:69-90.

4. Hohenberger P, Gretschel S. Gastric cancer. Lancet 2003;362:305-15.

5. Clarke MF, Fuller M. Stem cells and cancer: two faces of eve. Cell 2006;124:1111-5.

6. Visvader JE, Lindeman GJ. Cancer stem cells: current status and evolving complexities. Cell Stem Cell 2012;10:717-28.

7. Jordan CT, Guzman ML, Noble M. Cancer stem cells. N Engl J Med 2006;355:1253-61.

8. Furth J, Kahn MC, Breedis C. The transmission of leukemia of mice with a single cell. Am J Cancer 1937;31:276-82. 
9. Bonnet D, Dick JE. Human acute myeloid leukemia is organized as a hierarchy that originates from a primitive hematopoietic cell. Nat Med 1997;3:730-7.

10. Ricci-Vitiani L, Lombardi DG, Pilozzi E, Biffoni M, Todaro M, Peschle C, De Maria R. Identification and expansion of human coloncancer-initiating cells. Nature 2007;445:111-5.

11. Singh SK, Clarke ID, Terasaki M, Bonn VE, Hawkins C, Squire J, Dirks PB. Identification of a cancer stem cell in human brain tumors. Cancer Res 2003;63:5821-8.

12. Al-Hajj M, Wicha MS, Benito-Hernandez A, Morrison SJ, Clarke MF. Prospective identification of tumorigenic breast cancer cells. Proc Natl Acad Sci U S A 2003;100:3983-8.

13. Xu G, Shen J, Ou Yang X, Sasahara M, Su X. Cancer stem cells: the "heartbeat" of gastric cancer. J Gastroenterol 2013;48:781-97.

14. Singh SR. Gastric cancer stem cells: a novel therapeutic target. Cancer Lett 2013;338:110-9.

15. Vermeulen L, Todaro M, de Sousa Mello F, Sprick MR, Kemper K, Perez Alea M, Richel DJ, Stassi G, Medema JP. Single-cell cloning of colon cancer stem cells reveals a multi-lineage differentiation capacity. Proc Natl Acad Sci U S A 2008;105:13427-32.

16. Takaishi S, Okumura T, Tu S, Wang SS, Shibata W, Vigneshwaran R, Gordon SA, Shimada Y, Wang TC. Identification of gastric cancer stem cells using the cell surface marker CD44. Stem Cells 2009;27:1006-20.

17. Zhang C, Li C, He F, Cai Y, Yang H. Identification of CD44+CD24+ gastric cancer stem cells. J Cancer Res Clin Oncol 2011;137:167986.

18. Chen T, Yang K, Yu J, Meng W, Yuan D, Bi F, Liu F, Liu J, Dai B, Chen X, Wang F, Zeng F, Xu H, Hu J, Mo X. Identification and expansion of cancer stem cells in tumor tissues and peripheral blood derived from gastric adenocarcinoma patients. Cell Res 2012;22:24858.

19. Han ME, Jeon TY, Hwang SH, Y.S. Lee Y, Kim HJ, Shim HE, Yoon S, Baek SY, Kim BS, Kang CD, Oh SO. Cancer spheres from gastric cancer patients provide an ideal model system for cancer stem cell research. Cell Mol Life Sci 2011;68:3589-605.

20. Barker N, van Es JH, Kuipers J, Kujala P, van den Born M, Cozijnsen M, Haegebarth A, Korving J, Begthel H, Peters PJ, Clevers H. Identification of stem cells in small intestine and colon by marker gene Lgr5. Nature 2007;449:1003-7.

21. Barker N, Huch M, Kujala P, van de Wetering M, Snippert HJ, van Es JH, Sato T, Stange DE, Begthel H, van den Born M, Danenberg E, van den Brink S, Korving J, Abo A, Peters PJ, Wright N, Poulsom R, Clevers H. Lgr5(+ve) stem cells drive self-renewal in the stomach and build long-lived gastric units in vitro. Cell Stem Cell 2010;6:25-36.

22. Sato T, van Es JH, Snippert HJ, Stange DE, Vries RG, van den Born M, Barker N, Shroyer NF, van de Wetering M, Clevers H. Paneth cells constitute the niche for Lgr5 stem cells in intestinal crypts. Nature 2011;469:415-8.

23. Demitrack ES, Gifford GB, Keeley TM, Carulli AJ, VanDussen KL, Thomas D, Giordano TJ, Liu Z, Kopan R, Samuelson LC. Notch signaling regulates gastric antral LGR5 stem cell function. EMBO J 2015;34:2522-36.

24. Leushacke M, Tan SH, Wong A, Swathi Y, Hajamohideen A, Tan LT, Goh J, Wong E, Denil SLIJ, Murakami K, Barker N. Lgr5expressing chief cells drive epithelial regeneration and cancer in the oxyntic stomach. Nat Cell Biol 2017;19:774-86.

25. Jiang Y, He Y, Li H, Li HN, Zhang L, Hu W, Sun YM, Chen FL, Jin XM. Expressions of putative cancer stem cell markers ABCB1, ABCG2, and CD133 are correlated with the degree of differentiation of gastric cancer. Gastric Cancer 2012;15:440-50.

26. Hashimoto K, Aoyagi K, Isobe T, Kouhuji K, Shirouzu K. Expression of CD133 in the cytoplasm is associated with cancer progression and poor prognosis in gastric cancer. Gastric Cancer 2014;17:97-106.

27. Katsuno Y, Ehata S, Yashiro M, Yanagihara K, Hirakawa K, Miyazono K. Coordinated expression of REG4 and aldehyde dehydrogenase 1 regulating tumourigenic capacity of diffuse-type gastric carcinoma-initiating cells is inhibited by TGF-beta. $J$ Pathol 2012;228:391-404

28. Nguyen PH, Giraud J, Chambonnier L, Dubus P, Wittkop L, Belleannée G, Collet D, Soubeyran I, Evrard S, Rousseau B, Senant-Dugot N, Mégraud F, Mazurier F, Varon C. Characterization of biomarkers of tumorigenic and chemoresistant cancer stem cells in human gastric carcinoma. Clin Cancer Res 2017;23:1586-97.

29. Bang YJ, Van Cutsem E, Feyereislova A, Chung HC, Shen L, Sawaki A, Lordick F, Ohtsu A, Omuro Y, Satoh T, Aprile G, Kulikov E, Hill J, Lehle M, Rüschoff J, Kang YK; ToGA Trial Investigators. Trastuzumab in combination with chemotherapy versus chemotherapy alone for treatment of HER2-positive advanced gastric or gastro-oesophageal junction cancer (ToGA): a phase 3, open-label, randomised controlled trial. Lancet 2010;376:687-97.

30. Jiang J, Zhang Y, Chuai S, Wang Z, Zheng D, Xu F, Zhang Y, Li C, Liang Y, Chen Z. Trastuzumab (herceptin) targets gastric cancer stem cells characterized by CD90 phenotype. Oncogene 2012;31:671-82.

31. Ohkuma M, Haraguchi N, Ishii H, Mimori K, Tanaka F, Kim HM, Shimomura M, Hirose H, Yanaga K, Mori M. Absence of CD71 transferrin receptor characterizes human gastric adenosquamous carcinoma stem cells. Ann Surg Oncol 2012;19:1357-64.

32. Choi E, Lantz TL, Vlacich G, Keeley TM, Samuelson LC, Coffey RJ, Goldenring JR, Powell AE. Lrig1+ gastric isthmal progenitor cells restore normal gastric lineage cells during damage recovery in adult mouse stomach. Gut 2017; doi: 10.1136/gutjnl-2017-313874

33. Hayakawa Y, Ariyama H, Stancikova J, Sakitani K, Asfaha S, Renz BW, Dubeykovskaya ZA, Shibata W, Wang H, Westphalen CB, Chen X, Takemoto Y, Kim W, Khurana SS, Tailor Y, Nagar K, Tomita H, Hara A, Sepulveda AR, Setlik W, Gershon MD, Saha S, Ding L, Shen Z, Fox JG, Friedman RA, Konieczny SF, Worthley DL, Korinek V, Wang TC. Mist1 expressing gastric stem cells maintain the normal and neoplastic gastric epithelium and are supported by a perivascular stem cell niche. Cancer Cell 2015;28:800-14.

34. Quail DF, Joyce JA. Microenvironmental regulation of tumor progression and metastasis. Nat Med 2013;19:1423-37.

35. Ishimoto T, Miyake K, Nandi T, Yashiro M, Onishi N, Huang KK, Lin SJ, Kalpana R, Tay ST, Suzuki Y, Cho BC, Kuroda D, Arima K, Izumi D, Iwatsuki M, Baba Y, Oki E, Watanabe M, Saya H, Hirakawa K, Baba H, Tan P. Activation of transforming growth factor beta 1 signaling in gastric cancer-associated fibroblasts increases their motility, via expression of rhomboid 5 homolog 2, and ability to induce invasiveness of gastric cancer cells. Gastroenterology 2017;153:191-204.e16.

36. Leedham SJ, Brittan M, Preston SL, McDonald SA, Wright NA. The stomach periglandular fibroblast sheath: all present and correct. Gut 2006:55:295-6.

37. Hoffmann W. Stem cells, self-renewal and cancer of the gastric epithelium. Curr Med Chem 2012;19:5975-83.

38. Nabet BY, Qiu Y, Shabason JE, Wu TJ, Yoon T, Kim BC, Benci JL, DeMichele AM, Tchou J, Marcotrigiano J, Minn AJ. Exosome RNA 
unshielding couples stromal activation to pattern recognition receptor signaling in cancer. Cell 2017;170:352-66.e13.

39. Schofield R. The relationship between the spleen colony-forming cell and the haemopoietic stem cell. Blood Cells 1978;4:7-25.

40. Moore KA, Lemischka IR. Stem cells and their niches. Science 2006;311:1880-5.

41. Boral D, Nie D. Cancer stem cells and niche mircoenvironments. Front Biosci (Elite Ed) 2012;4:2502-14.

42. Yi SY, Hao YB, Nan KJ, Fan TL. Cancer stem cells niche: a target for novel cancer therapeutics. Cancer Treat Rev 2013;39:290-6.

43. Kalluri R. The biology and function of fibroblasts in cancer. Nat Rev Cancer 2016;16:582-98.

44. Hasegawa T, Yashiro M, Nishii T, Matsuoka J, Fuyuhiro Y, Morisaki T, Fukuoka T, Shimizu K, Shimizu T, Miwa A, Hirakawa K. Cancerassociated fibroblasts might sustain the stemness of scirrhous gastric cancer cells via transforming growth factor-beta signaling. Int $J$ Cancer 2014;134:1785-95.

45. Bie Q, Zhang B, Sun C, Ji X, Barnie PA, Qi C, Peng J, Zhang D, Zheng D, Su Z, Wang S, Xu H. IL-17B activated mesenchymal stem cells enhance proliferation and migration of gastric cancer cells. Oncotarget 2017;8:18914-23.

46. Hayakawa Y, Sakitani K, Konishi M, Asfaha S, Niikura R, Tomita H, Renz BW, Tailor Y, Macchini M, Middelhoff M, Jiang Z, Tanaka T, Dubeykovskaya ZA, Kim W, Chen X, Urbanska AM, Nagar K, Westphalen CB, Quante M, Lin CS, Gershon MD, Hara A, Zhao CM, Chen D, Worthley DL, Koike K, Wang TC. Nerve growth factor promotes gastric tumorigenesis through aberrant cholinergic signaling. Cancer Cell 2017;31:21-34.

47. Sawaki A, Ohashi Y, Omuro Y, Satoh T, Hamamoto Y, Boku N, Miyata Y, Takiuchi H, Yamaguchi K, Sasaki Y, Nishina T, Satoh A, Baba E, Tamura T, Abe T, Hatake K, Ohtsu A. Efficacy of trastuzumab in Japanese patients with HER2-positive advanced gastric or gastroesophageal junction cancer: a subgroup analysis of the Trastuzumab for Gastric Cancer (ToGA) study. Gastric Cancer 2012;15:31322.

48. Yamaguchi K, Sawaki A, Doi T, Satoh T, Yamada Y, Omuro Y, Nishina T, Boku N, Chin K, Hamamoto Y, Takiuchi H, Komatsu Y, Saji S, Koizumi W, Miyata Y, Sato A, Baba E, Tamura T, Abe T, Ohtsu A. Efficacy and safety of capecitabine plus cisplatin in Japanese patients with advanced or metastatic gastric cancer: subset analyses of the AVAGAST study and the ToGA study. Gastric Cancer 2013;16:175-82.

49. Wilke H, Muro K, Van Cutsem E, Oh SC, Bodoky G, Shimada Y, Hironaka S, Sugimoto N, Lipatov O, Kim TY, Cunningham D, Rougier P, Komatsu Y, Ajani J, Emig M, Carlesi R, Ferry D, Chandrawansa K, Schwartz JD, Ohtsu A; RAINBOW Study Group. Ramucirumab plus paclitaxel versus placebo plus paclitaxel in patients with previously treated advanced gastric or gastro-oesophageal junction adenocarcinoma (RAINBOW): a double-blind, randomised phase 3 trial. Lancet Oncol 2014;15:1224-35.

50. Shitara K, Muro K, Shimada Y, Hironaka S, Sugimoto N, Komatsu Y, Nishina T, Yamaguchi K, Segawa Y, Omuro Y, Tamura T, Doi T, Yukisawa S, Yasui H, Nagashima F, Gotoh M, Esaki T, Emig M, Chandrawansa K, Liepa AM, Wilke H, Ichimiya Y, Ohtsu A. Subgroup analyses of the safety and efficacy of ramucirumab in Japanese and Western patients in RAINBOW: a randomized clinical trial in secondline treatment of gastric cancer. Gastric Cancer 2016;19:927-38

51. Topalian SL, Drake CG, Pardoll DM. Immune checkpoint blockade: a common denominator approach to cancer therapy. Cancer Cell 2015;27:450-61.

52. Kang YK, Satoh T, Ryu MH, Chao Y, Kato K, Chung HC, Chen JS, Muro K, Kang WK, Yoshikawa T, Oh SC, Tamura T, Lee KW, Boku N, Chen LT. Nivolumab (ONO-4538/BMS-936558) as salvage treatment after second or later-line chemotherapy for advanced gastric or gastro-esophageal junction cancer (AGC): a double-blinded, randomized, phase III trial. J Clin Oncol 2017;35:2.

53. Ishimoto T, Nagano O, Yae T, Tamada M, Motohara T, Oshima H, Oshima M, Ikeda T, Asaba R, Yagi H, Masuko T, Shimizu T, Ishikawa T, Kai K, Takahashi E, Imamura Y, Baba Y, Ohmura M, Suematsu M, Baba H, Saya H. CD44 variant regulates redox status in cancer cells by stabilizing the xCT subunit of system xc(-) and thereby promotes tumor growth. Cancer Cell 2011;19:387-400.

54. Nagano O, Okazaki S, Saya H. Redox regulation in stem-like cancer cells by CD44 variant isoforms. Oncogene 2013;32:5191-8.

55. Wada T, Ishimoto T, Seishima R, Tsuchihashi K, Yoshikawa M, Oshima H, Oshima M, Masuko T, Wright NA, Furuhashi S, Hirashima K, Baba H, Kitagawa Y, Saya H, Nagano O. Functional role of CD44v-xCT system in the development of spasmolytic polypeptideexpressing metaplasia. Cancer Sci 2013;104:1323-9.

56. Smith LM, Nesterova A, Ryan MC, Duniho S, Jonas M, Anderson M, Zabinski RF, Sutherland MK, Gerber HP, Van Orden KL, Moore PA, Ruben SM, Carter PJ. CD133/prominin-1 is a potential therapeutic target for antibody-drug conjugates in hepatocellular and gastric cancers. Br J Cancer 2008;99:100-9.

57. Roesch A, Fukunaga-Kalabis M, Schmidt EC, Zabierowski SE, Brafford PA, Vultur A, Basu D, Gimotty P, Vogt T, Herlyn M. A temporarily distinct subpopulation of slow-cycling melanoma cells is required for continuous tumor growth. Cell 2010;141:583-94.

58. Xu YY, Guo M, Yang LQ, Zhou F, Yu C, Wang A, Pang TH, Wu HY, Zou XP, Zhang WJ, Wang L, Xu GF, Huang Q. Regulation of CD44v6 expression in gastric carcinoma by the IL-6/STAT3 signaling pathway and its clinical significance. Oncotarget 2017;8:45848-61.

59. Phesse TJ, Sansom OJ. Lgr5 joins the club of gastric stem cell markers in the corpus. Nat Cell Biol 2017;19:752-4.

60. Li XB, Yang G, Zhu L, Tang YL, Zhang C, Ju Z, Yang X, Teng Y. Gastric Lgr5(+) stem cells are the cellular origin of invasive intestinaltype gastric cancer in mice. Cell Res 2016;26:838-49.

61. Gong X, Azhdarinia A, Ghosh SC, Xiong W, An Z, Liu Q, Carmon KS. LGR5-targeted antibody-drug conjugate eradicates gastrointestinal tumors and prevents recurrence. Mol Cancer Ther 2016;15:1580-90.

62. Zhang L, Guo X, Zhang D, Fan Y, Qin L, Dong S, Zhang L. Upregulated miR-132 in Lgr5(+) gastric cancer stem cell-like cells contributes to cisplatin-resistance via SIRT1/CREB/ABCG2 signaling pathway. Mol Carcinog 2017;56:2022-34.

63. Wen L, Chen XZ, Yang K, Chen ZX, Zhang B, Chen JP, Zhou ZG, Mo XM, Hu JK. Prognostic value of cancer stem cell marker CD133 expression in gastric cancer: a systematic review. PLoS One 2013;8:e59154. 